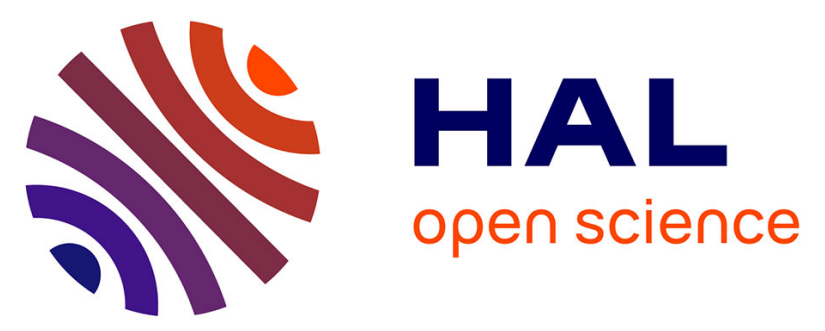

\title{
Analysis, Modeling and Neural Network Traction Control of an Electric Vehicle without Differential Gears
}

\author{
Abdelhakim Haddoun, Mohamed Benbouzid, Demba Diallo, Rachid
}

Abdessemed, Jamel Ghouili, Kamel Srairi

\section{- To cite this version:}

Abdelhakim Haddoun, Mohamed Benbouzid, Demba Diallo, Rachid Abdessemed, Jamel Ghouili, et al.. Analysis, Modeling and Neural Network Traction Control of an Electric Vehicle without Differential Gears. IEEE IEMDC'07, May 2007, Antalya, Turkey. pp.854-859. hal-00531259

\section{HAL Id: hal-00531259 \\ https://hal.science/hal-00531259}

Submitted on 2 Nov 2010

HAL is a multi-disciplinary open access archive for the deposit and dissemination of scientific research documents, whether they are published or not. The documents may come from teaching and research institutions in France or abroad, or from public or private research centers.
L'archive ouverte pluridisciplinaire HAL, est destinée au dépôt et à la diffusion de documents scientifiques de niveau recherche, publiés ou non, émanant des établissements d'enseignement et de recherche français ou étrangers, des laboratoires publics ou privés. 


\title{
Analysis, Modeling and Neural Network Traction Control of an Electric Vehicle without Differential Gears
}

\author{
A. Haddoun, M.E.H. Benbouzid, Senior Member, IEEE, D. Diallo, Senior Member, IEEE, R. Abdessemed, J. Ghouili and K. Srairi
}

\begin{abstract}
This paper presents system analysis, modeling and simulation of an EV with two independent rear wheel drives. The traction control system is designed to guarantee the $\mathrm{EV}$ dynamics and stability in case of no differential gears. Using two electrics in-wheel motors give the possibility to have a torque and speed control in each wheel. This control level improves the EV stability and the safety. The proposed traction control system uses the vehicle speed, which is different from wheels speed characterized by slip in the driving mode, an input. In this case, a generalized neural network algorithm is proposed to estimate the vehicle speed. In terms of the analysis and the simulations carried out, the conclusion can be drawn that the proposed system is feasible. Simulation results on a test vehicle propelled by two $37-\mathrm{kW}$ induction motors showed that the proposed control approach operates satisfactorily.
\end{abstract}

Index Terms-Electric vehicle, electric motor, speed estimation, neural networks, traction control.

\section{INTRODUCTION}

Recently, Electric Vehicles (EVs) including fuel-cell and hybrid vehicles have been developed very rapidly as a solution of energy and environmental problems. From the point of view of control engineering, EVs have much attractive potential. Since electric motors and inverters are utilized in drive system, they have great advantages over internal combustion engine vehicles such as quick torque response and individual control of each wheel. Although several control methods have been proposed using these merits, their controllers depend on some immeasurable parameters such as vehicle velocity, slip angle, etc.

The principal constraints in vehicle design for personal mobility are the development of a nonpolluting high safety and comfortable vehicle. Taking into account these constraints, our interest has been focused on the $2 \times 4$ electrical vehicles, with independent driving in-wheel motor at the front and with classical motors on the rear drive shaft.

A. Haddoun ${ }^{*}$ and M.E.H. Benbouzid are with the Laboratoire d'Ingénierie Mécanique et Electrique (LIME), University of Western Brittany, Rue de Kergoat - BP 93169, 29231 Brest Cedex 3, France (phone: +332980180 07; fax: +332980166 43; e-mail: m.benbouzid@ieee.org).

*A. Haddoun is also with the University of Oum El Bouaghi, 04000 Oum El Bouaghi, Algeria.

D. Diallo is with the Laboratoire de Génie Electrique de Paris (LGEP), CNRS UMR 8507, University Paris Sud, Supélec, University Paris VI, Plateau du Moulon, 91192 Gif-Sur-Yvette, France (e-mail: ddiallo@ieee.org).

R. Abdessemed is with the University of Batna, 05000 Batna, Algeria.

J. Ghouili is with the GRET Research Group, Engineering Faculty, University of Moncton, Moncton, New Brunswick, Canada.

$\mathrm{K}$. Srairi is with the University of Biskra, 07000 Biskra, Algeria.
Torque control can be ensured by the inverter, so this vehicle does not require differential gears. However, one of the main issues in the design of this vehicle (without mechanical differential) is to assume the car stability. During normal driving condition, all the drive wheel system requires a symmetrical distribution of torque in both sides. This symmetrical distribution is not sufficient when the adherence coefficient of tires is changing: the wheels have different speeds; so the needs for traction control system [1]. This is still an open problem as illustrated by a limited available literature [2-3].

To address this open problem, this paper proposes a neural network traction control approach of an electrical differential system for an EV propelled by two induction motor drives (one for each wheel). In recent years, neural network concepts have become an active research area. Because of the necessity for adaptive abilities in a network learning process, applying neural networks to system identification and control dynamics has become a promising alternative to process control [4]. Neural networks can be applied to control and identify the nonlinear systems since they approximate any desired degree of accuracy with a wide range of nonlinear model.

The rotor speed information of an induction motor in the vector control method is obtained using speed sensors. These sensors are usually expensive and bulky; therefore, the cost and size of the drive systems are increased. Since 1980s the concept of rotor speed estimation has been studied extensively where the instantaneous stator voltages and currents were used to estimate the speed of an induction motor such as in model reference adaptive system, extended Kalman filter algorithm [5]. However, induction motors have highly nonlinear dynamic behaviors and their parameters vary with time and operating conditions. Therefore, it is difficult to obtain accurate speed estimates with these methods. In this paper, a new speed estimation method of an induction motor is proposed where a Recurrent Neural Network (RNN) with two hidden layers is used [5-6]. This neural network was initially proposed by Jordan and then modified by Elman. It is also known as Jordan-Elman neural network in the literature. The multilayer and recurrent structure of ENN makes it robust under parameter variations and system noises. This ENN speed estimator can be used in induction motors vector control to eliminate expensive speed transducers [6].

Moreover, the proposed RNN-based speed estimator, which replaces the speed sensor in vector control approach scheme takes into account the vehicle aerodynamics, and is not applied to the sole induction motors. It should be noted 
that the induction motor has been adopted for the EV propulsion because it seems to be the candidate that better fulfils the major requirements for EVs propulsion [7].

\section{VEHICLE MODEL}

Compared to previous works, the proposed control strategy takes into account the vehicle aerodynamics, and is not applied to the sole induction motors. This model is based on the principles of vehicle mechanics and aerodynamics [8]. The total tractive effort is then given by

$$
F_{t e}=F_{r r}+F_{a d}+F_{h c}+F_{l a}+F_{w a}
$$

Where $F_{r r}=$ is the rolling resistance force;

$F_{a d}=$ is the aerodynamic drag;

$F_{h c}=$ is the hill climbing force;

$F_{l a}=$ is the force required to give linear acceleration;

$F_{w a}=$ is the force required to give angular acceleration to the rotating motor.

It should be noted that $F_{l a}$ and $F_{w a}$ will be negative if the vehicle is slowing down and that $F_{h c}$ will be negative if it is going downhill. The power required to drive a vehicle at a speed $v$ has to compensate counteracting forces.

$P_{t e}=v F_{t e}=v\left(F_{r r}+F_{a d}+F_{h c}+F_{l a}+F_{w a}\right)$

\section{INDUCTION MOTOR MODELING}

\section{A. Nomenclature}

$V_{d s}\left(V_{q s}\right)=d$-axis ( $q$-axis) stator voltages;

$i_{d s}\left(i_{q s}\right)=d$-axis $q$-axis) stator currents;

$\lambda_{d r}\left(\lambda_{q r}\right)=d$-axis ( $q$-axis) rotor flux linkages;

$R_{S}\left(R_{r}\right) \quad=$ Stator (rotor) resistance;

$L_{s}\left(L_{r}\right) \quad=$ Stator (rotor) inductance;

$L_{m} \quad=$ Magnetizing inductance;

$L_{\sigma} \quad=$ Leakage inductance $\left(L_{\sigma}=L_{s}-L_{m}{ }^{2} / L_{r}\right)$;

$\omega_{e}\left(\omega_{r}\right)=$ Stator (rotor) electrical speed;

$\Omega \quad=$ Rotor speed $\left(\omega_{r} / \mathrm{p}\right) ;$

$\omega_{s l} \quad=$ Slip frequency, $\omega_{s l}=\omega_{s}-\omega_{r}$

$B \quad=$ Motor damping ratio;

$p \quad=$ pole-pair number.

$$
\left\{\begin{array}{l}
k_{1}=\frac{R_{s}}{L_{\sigma}}+\frac{R_{r} L_{m}^{2}}{L_{r}^{2} L_{\sigma}}, k_{2}=\frac{R_{r} L_{m}}{L_{r}^{2} L_{\sigma}}, k_{3}=\frac{L_{m}}{L_{r} L_{\sigma}}, \\
k_{4}=\frac{R_{r} L_{m}}{L_{r}}, k_{5}=\frac{R_{r}}{L_{r}}, k_{6}=\frac{1}{L_{\sigma}}, k_{t}=\frac{3}{2} p \frac{L_{m}}{L_{r}}
\end{array}\right.
$$

\section{B. Induction Motor Dynamic Model}

Generally, dynamic modeling of an induction motor drive is based on rotating reference-frame theory and a linear technique. A system configuration of an induction motor drive is shown in Fig. 1. This motor drive consists of an induction motor, a bang-bang current-controlled pulse width modulated (PWM) inverter, a field-orientation mechanism, a coordinate translator and a speed controller. The electrical dynamics of an induction motor in the synchronously rotating reference frame ( $d$-q-axis) can be expressed by (3-5) [4-9].

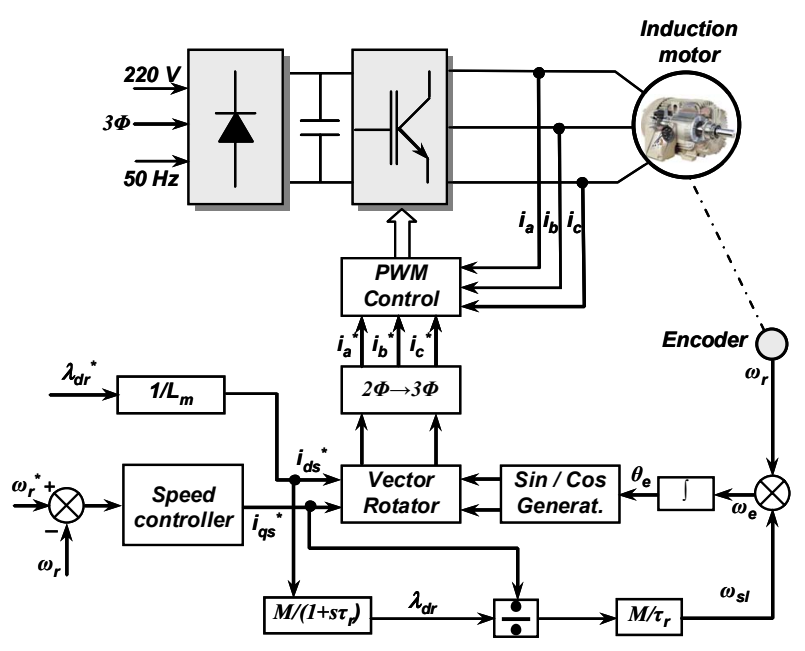

Fig. 1. Direct field-oriented induction motor drive.

$\frac{d}{d t}\left[\begin{array}{c}i_{d s} \\ i_{q s} \\ \lambda_{d r} \\ \lambda_{q r}\end{array}\right]=\left[\begin{array}{cccc}-k_{1} & \omega_{e} & k_{2} & \omega_{r} k_{3} \\ -\omega_{e} & -k_{1} & -\omega_{r} k_{3} & k_{2} \\ k_{4} & 0 & -k_{5} & \omega_{s l} \\ 0 & k_{4} & -\omega_{s l} & -k_{5}\end{array}\right]\left[\begin{array}{c}i_{d s} \\ i_{q s} \\ \lambda_{d r} \\ \lambda_{q r}\end{array}\right]+k_{6}\left[\begin{array}{c}V_{d s} \\ V_{q s} \\ 0 \\ 0\end{array}\right]$

$\frac{d \omega_{r}}{d t}=-\frac{B}{J} \omega_{r}-\frac{1}{J}\left(T_{m}-T_{L}\right)$

$T_{m}=k_{t}\left(\lambda_{d r} i_{q s}-\lambda_{q r} i_{d s}\right)$

\section{NEURAL NeTWORK Traction CONTROL}

\section{A. Why Neural Network Traction Control?}

Recent development in Artificial Neural Network (ANN) traction control technology has made it possible to train an ANN to represent a variety of complicated nonlinear systems. ANN is the simulation of human brain nervous system and is constructed of artificial neurons and their interconnections. Like the human brain the ANN can be trained to solve the most complex nonlinear problems with variable parameters. There have been several applications of ANN in AC drive systems such as adaptive flux control, current control, speed control, and field oriented control [10].

\section{B. The Neural Network Controller}

The dynamic behavior of an induction motor can be described by voltage and current models (with decoupling control $\lambda_{q r}=0$ and $\lambda_{d r}=\lambda=$ constant) is derived from (3-5).

$$
\left\{\begin{array}{l}
\frac{d i_{d s}}{d t}=-k_{1} i_{d s}+\omega_{e} i_{q s}+k_{2} \lambda_{d r}+k_{6} V_{d s} \\
\frac{d i_{q s}}{d t}=-k_{1} i_{q s}-\omega_{e} i_{d s}-k_{2} \lambda_{d r}+k_{6} V_{q s} \\
\frac{d \lambda_{d r}}{d t}=-k_{5} \lambda_{d r}+k_{4} i_{d s} \\
T_{e}=k_{t} \lambda_{d r} i_{q s}
\end{array}\right.
$$


The RNN model based in speed estimator replaces the adaptive current model. In this case, each output neuron uses the linear activation function. The solution of the voltage model generates the desired flux components. These signals are compared with the RNN output signals and the weights are trained on-line so that the error $\xi(k+1)$ tends to zero. It is assumed that the training speed is fast enough so that the estimated speed and actual speed can track well [11]. The current model equations can be discretized and written as

$\left[\begin{array}{c}\lambda_{d r}^{s}(k+1) \\ \lambda_{q r}^{s}(k+1)\end{array}\right]=\left[\begin{array}{cc}1-\frac{T_{s}}{T_{r}} & -\omega_{r} T_{s} \\ \omega_{r} T_{s} & 1-\frac{T_{s}}{T_{r}}\end{array}\right]\left[\begin{array}{l}\lambda_{d r}^{s}(k) \\ \lambda_{q r}^{s}(k)\end{array}\right]+\left[\begin{array}{cc}\frac{L_{m} T_{s}}{T_{r}} & 0 \\ 0 & \frac{L_{m} T_{s}}{T_{r}}\end{array}\right]\left[\begin{array}{l}i_{d s}^{s}(k) \\ i_{q s}^{s}(k)\end{array}\right]$

Where $T_{S}$ is the sampling time, $L_{m}$ the magnetizing inductance, and $T_{r}$ the rotor time constant. The above equation can also be written in the form

$\left[\begin{array}{l}\lambda_{d r}^{s}(k+1) \\ \lambda_{q r}^{s}(k+1)\end{array}\right]=\left[\begin{array}{ll}W_{11} & W_{21} \\ W_{12} & W_{22}\end{array}\right]\left[\begin{array}{l}\lambda_{d r}^{s}(k) \\ \lambda_{q r}^{s}(k)\end{array}\right]+\left[\begin{array}{cc}W_{31} & 0 \\ 0 & W_{32}\end{array}\right]\left[\begin{array}{l}i_{d s}^{s}(k) \\ i_{q s}^{s}(k)\end{array}\right](8)$

Where $W_{11}=1-T_{s} / T_{r}, W_{21}=-\omega_{r} T_{s}, W_{12}=\omega_{r} T_{s}, W_{22}=1-$ $T_{s} / T_{r}$, and $W_{31}=L_{m} T_{s} / T_{r}$.

The internal structure of the designed RNN speed estimator is shown in Fig. 2, where black circles represent context nodes and white circles represent the input, hidden and output nodes [11]. The RNN with a linear transfer function of unity gain satisfies equation (11). Note that out of the six weights in the network, only $W_{21}$ and $W_{12}$ (circled in the figure) contain the speed term; therefore, for speed estimation, it is sufficient if these weights are considered trainable, keeping the other weights constant (assuming that $T_{r}$ and $L_{m}$ are constants) for speed estimation. However, if all the weights are considered trainable, the speed as well as the rotor time constant can be tuned.

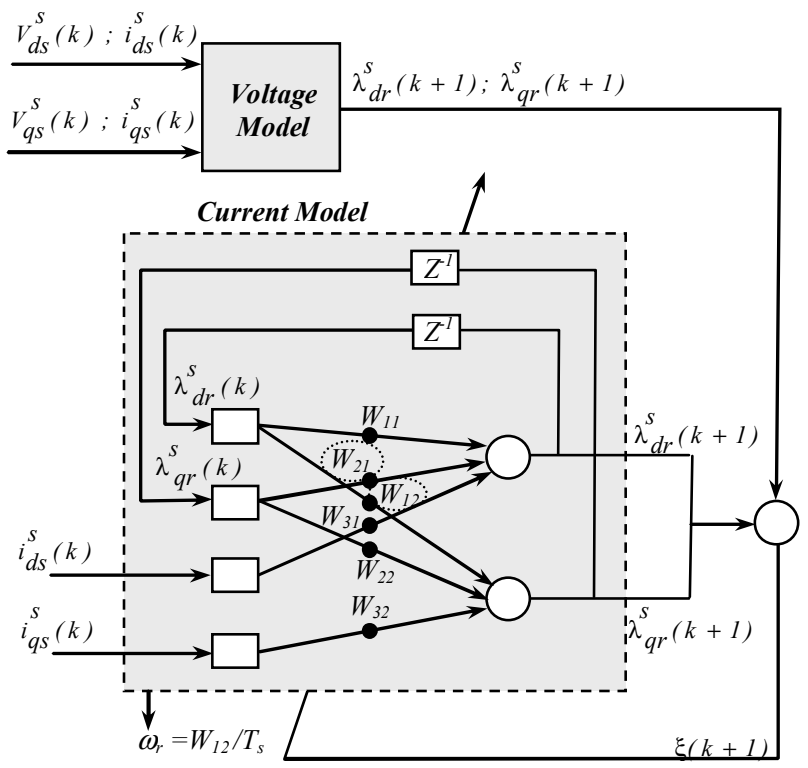

Fig. 2. Internal structure of the RNN estimator.

\section{THE ELECTRIC DifFERENTIAL AND ITS IMPLEMENTATION}

Figure 3 illustrates the implemented system (electric and mechanical components) in the Matlab-Simulink ${ }^{\circledR}$ environment.

The proposed control system principle could be summarized as follows: (1) A speed network control is used to control each motor torque; (2) The speed of each rear wheel is controlled using speeds difference feedback. Since the two rear wheels are directly driven by two separate motors, the speed of the outer wheel will require being higher than the speed of the inner wheel during steering maneuvers (and vice-versa). This condition can be easily met if the speed estimator is used to sense the angular speed of the steering wheel. The common reference speed $\omega_{\text {ref }}$ is then set by the accelerator pedal command. The actual reference speed for the left drive $\omega_{\text {ref-left }}$ and the right drive $\omega_{\text {ref-right }}$ are then obtained by adjusting the common reference speed $\omega_{\text {ref }}$ using the output signal from the RNN speed estimator. If the vehicle is turning right, the left wheel speed is increased and the right wheel speed remains equal to the common reference speed $\omega_{\text {ref. }}$. If the vehicle is turning left the right wheel speed is increased and the left wheel speed remains equal to the common reference speed $\omega_{\text {ref }}[12-13]$.

Usually, a driving trajectory is quite enough for an analysis of the vehicle system model. We have therefore adopted the Ackermann-Jeantaud steering model as it is widely used as driving trajectory. In fact, Ackermann steering geometry is a geometric arrangement of linkages in the steering of a car or other vehicle designed to solve the problem of wheels on the inside and outside of a turn needing to trace out circles of different radii. Modern cars do not use pure Ackermann-Jeantaud steering, partly because it ignores important dynamic and compliant effects, but the principle is sound for low speed maneuvers [14]. It is illustrated in Fig. 4.

From this model, the following characteristic can be calculated.

$$
R=\frac{L}{\tan \delta}
$$

Where $\delta$ is the steering angle. Therefore, each wheel drive linear speed is given by

$\left\{\begin{array}{l}V_{1}=\omega_{V}(R-d / 2) \\ V_{2}=\omega_{V}(R+d / 2)\end{array}\right.$

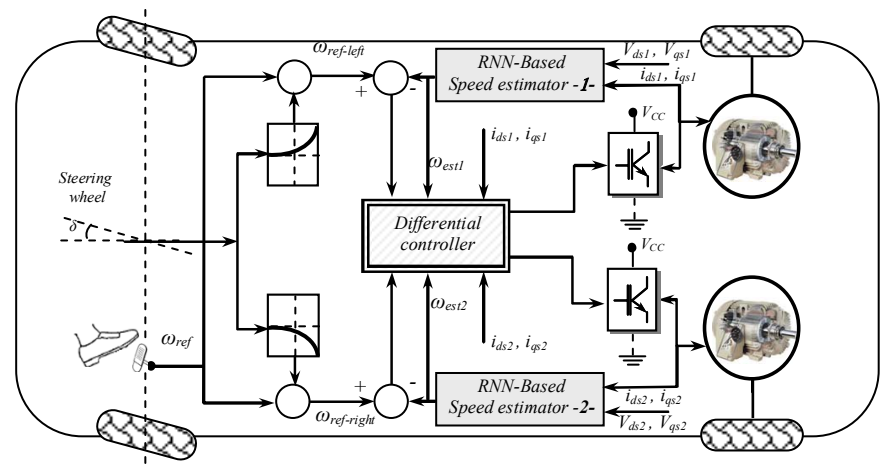

Fig. 3. EV propulsion and control systems schematic diagram. 


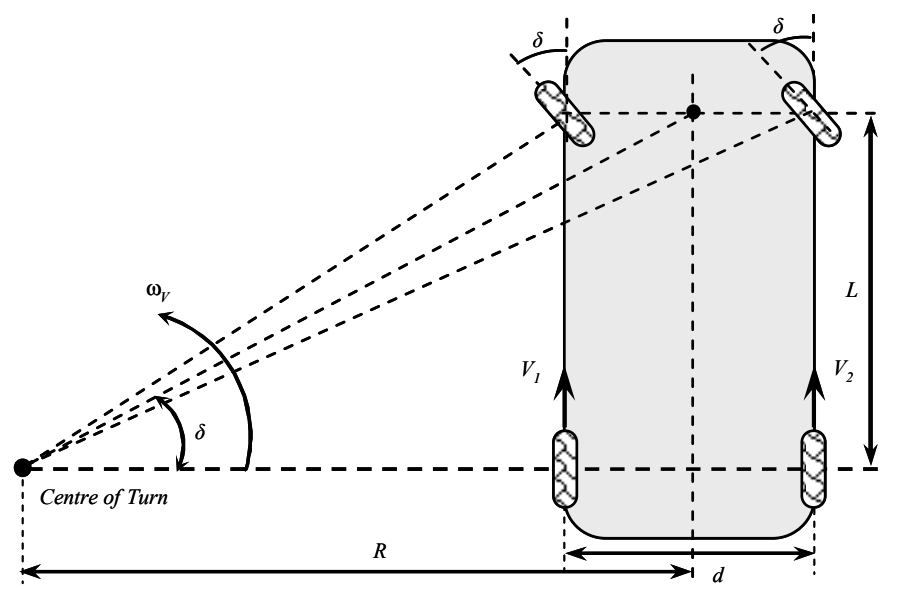

Fig. 4. Driving trajectory model.

and their angular speed by

$$
\left\{\begin{array}{l}
\omega_{e s t 1}=\frac{L-(d / 2) \tan \delta}{L} \omega_{V} \\
\omega_{e s t 2}=\frac{L+(d / 2) \tan \delta}{L} \omega_{V}
\end{array}\right.
$$

The difference between wheel drive angular speeds is then

$$
\Delta \omega=\omega_{e s t 1}-\omega_{e s t 2}=-\frac{d \tan \delta}{L} \omega_{V}
$$

and the steering angle indicates the trajectory direction.

$$
\left\{\begin{array}{l}
\delta>0 \Rightarrow \text { Turn left } \\
\delta=0 \Rightarrow \text { Straight ahead } \\
\delta<0 \Rightarrow \text { Turn right }
\end{array}\right.
$$

In accordance with the above described equation, Fig. 5 show the electric differential system block diagram as used for simulations.

\section{SimUlation RESUltS}

Numerical simulations have been carried out on an EV propelled by two $37-\mathrm{kW}$ induction motor drives which ratings are summarized in the appendix. In the appendix are also given the electrical vehicle mechanical and aerodynamic characteristics. The objectives of the carried out simulations are to assess the efficiency and dynamic performances of the proposed neural network control strategy.

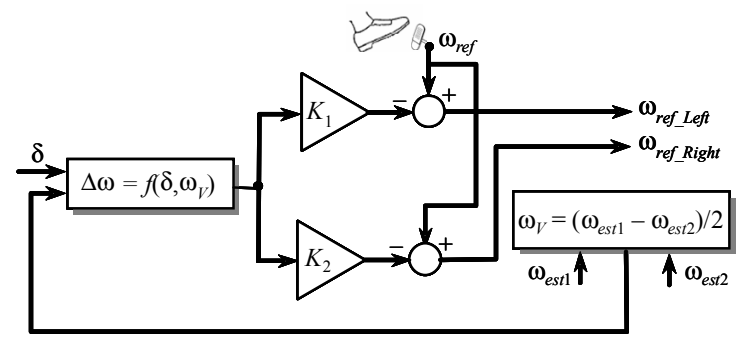

Fig. 5. Block diagram of the electric differential system.
The test cycle is the urban ECE-15 cycle (Fig. 6) [15]. A driving cycle is a series of data points representing the vehicle speed versus time. This driving cycle represents urban driving. It is characterized by low vehicle speed (maximum $50 \mathrm{~km} / \mathrm{h}$ ) and is useful for testing small electrical vehicles performance.

The electric differential performance are first illustrated by Fig. 7 that shows each wheel drive speeds during steering for $0<t<1180 \mathrm{sec}$. It is obvious that the electric differential operates satisfactorily.

Figures 8 and 9 illustrate the EV dynamics, respectively, the flux $\left(\lambda_{d r}\right)$ in each induction motor and the developed torque on the left and right wheel drives, with changes in the acceleration pedal position (Fig 10) and a varied road profile (rising and downward portions). It should be noticed that flux and torque variations are as large as are the variations of the accelerator pedal and the road profile.

The RNN speed estimator performances are illustrated by Fig. 11 that shows the measured speed and the estimated one.

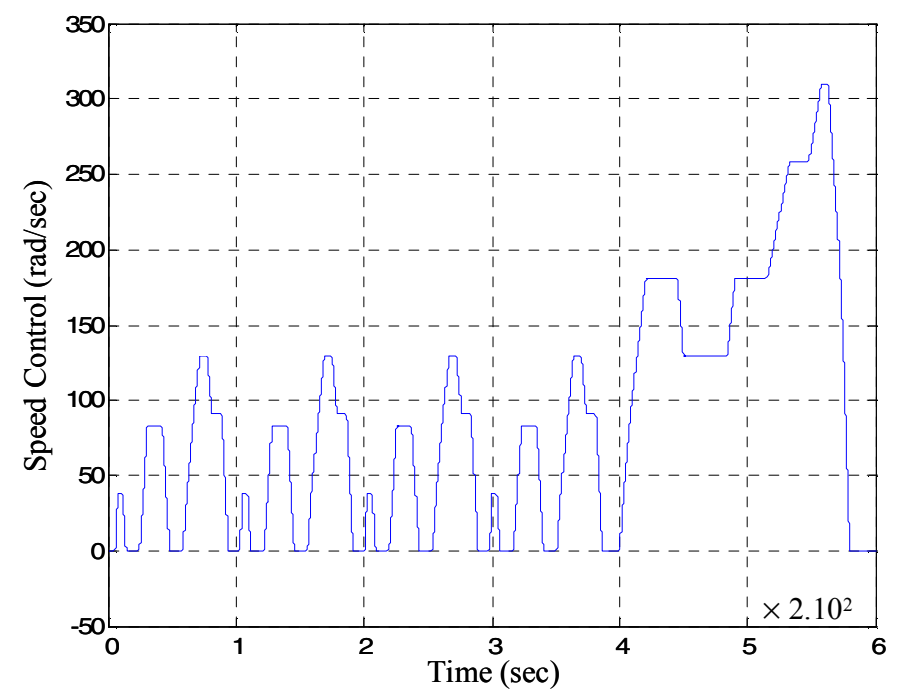

Fig. 6. European urban driving schedule ECE-15.

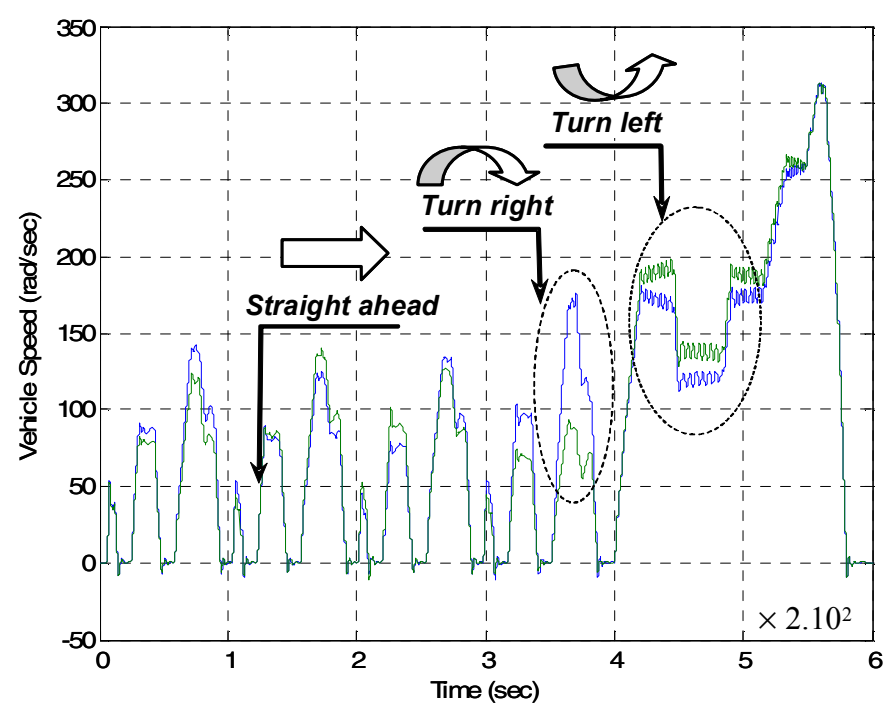

Fig. 7. Vehicle wheels speed. 


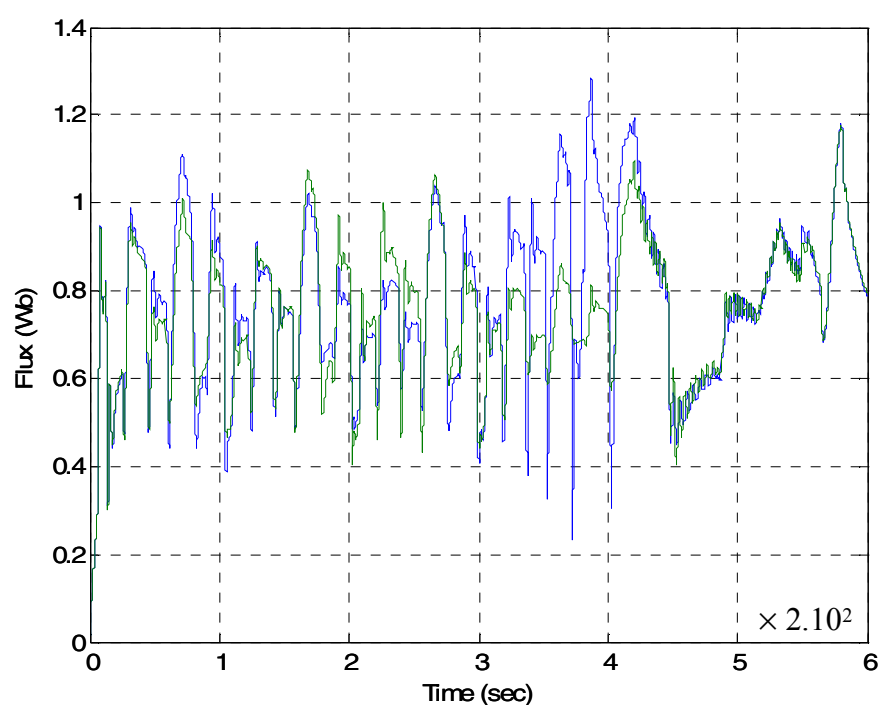

Fig. 8. Flux $\lambda_{d r}$.

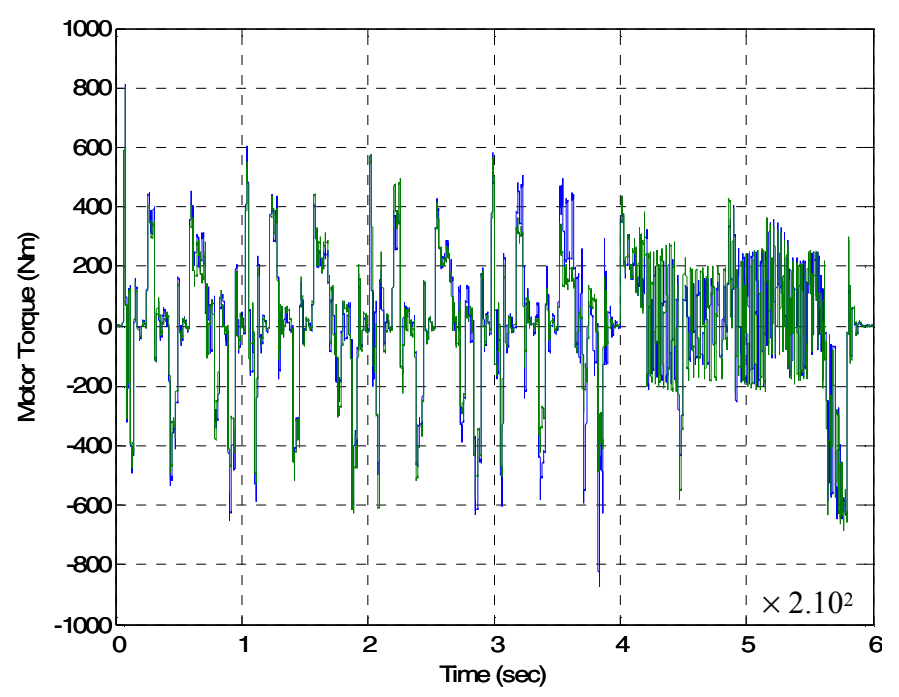

Fig. 9. Motor torque.

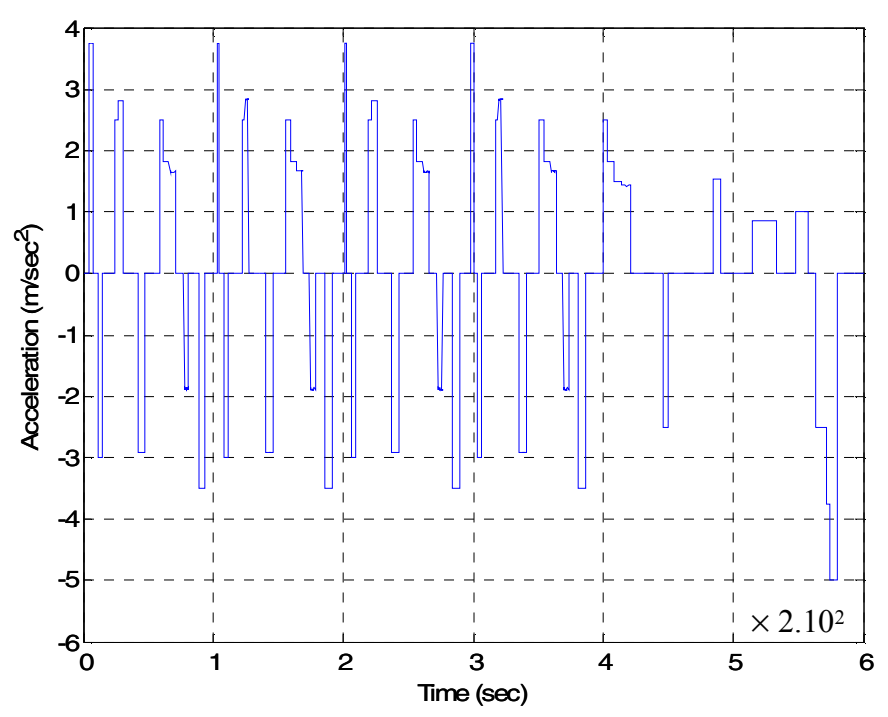

Fig. 10. Acceleration pedal position.

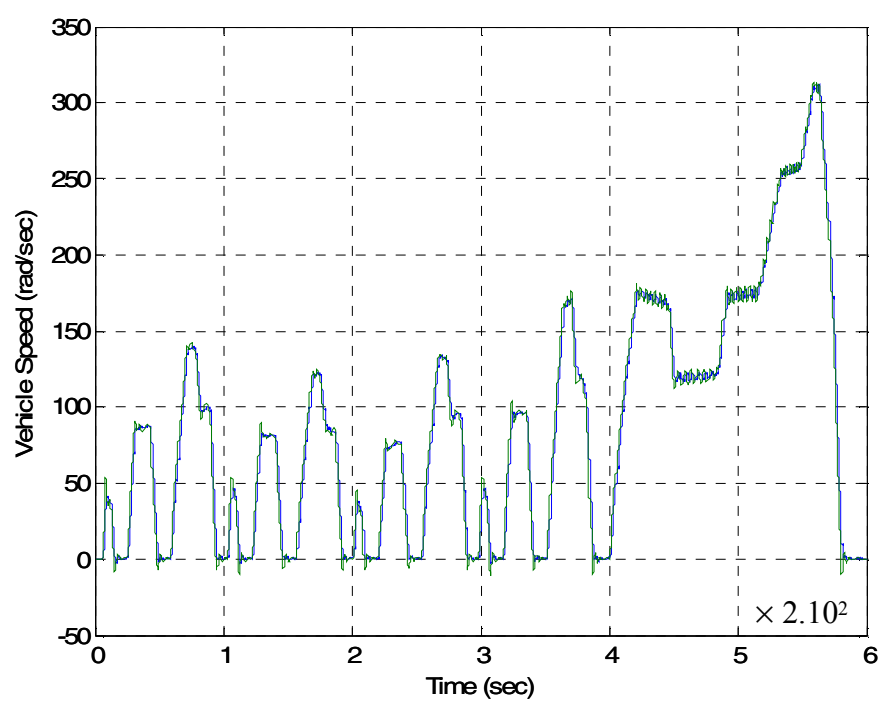

Fig. 11. Estimated and measured vehicle speed.

Figure 12 illustrates the power required to move the EV. To find the power taken from the battery to provide the tractive effort, we have to be able to find various efficiencies at all operating points.

\section{CONCLUSION}

In this paper, a neural network traction control algorithm for an electrical vehicle with two separate wheel drives has been proposed. This algorithm is necessary to improve the EV steerability and stability during trajectory changes. An electrical differential was implemented and take account of the speed difference between the two wheels when cornering. Moreover, as traction control systems impose a very precise knowledge of the vehicle dynamics, a vehicle dynamics model was exhaustively detailed and applied.

Numerical simulations have been carried out, on an EV propelled by two $37-\mathrm{kW}$ induction motor drives. The test cycle was in our case the urban ECE-15 cycle.

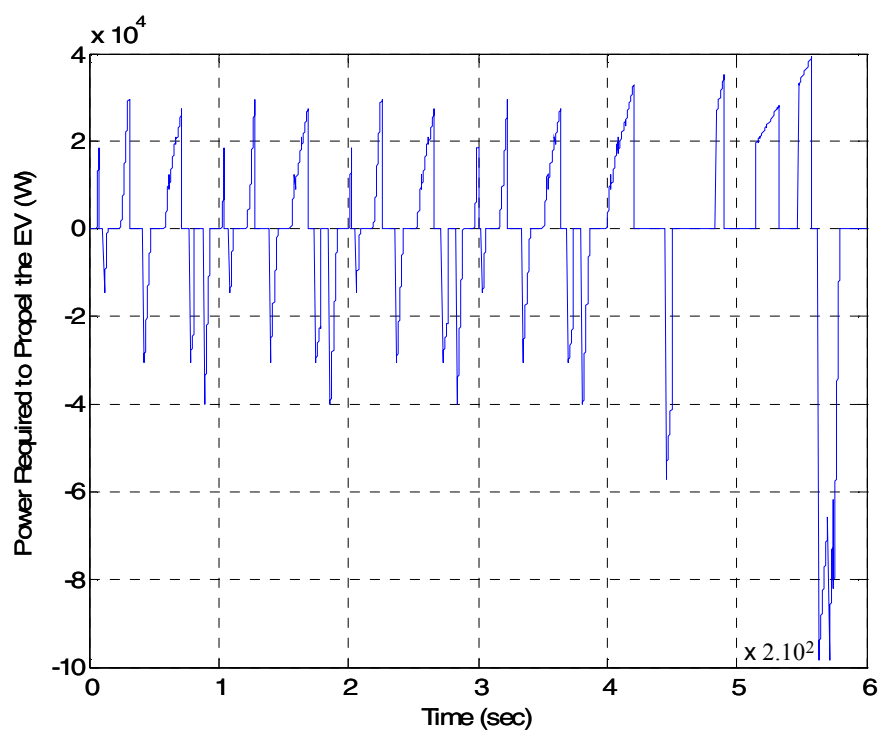

Fig. 12. Power required to propel the EV. 
During traction and regenerative braking, a correlation of traction control with motor performances has been realized. The obtained results seem to be very promising.

The neural network controller (RNN) speed estimator eliminates the need for an expensive speed transducer with a reasonable accuracy. It is shown that the proposed method estimates the speed accurately over the entire speed range from zero to full speed. Moreover, it has robust speed estimation performance even at step load change or under variable speed operation.

\section{APPENDIX}

RATED DATA OF THE SIMULATED INDUCTION MOTOR

$37 \mathrm{~kW}, 50 \mathrm{~Hz}, 400 / 230 \mathrm{~V}, 64 / 111 \mathrm{~A}, 24.17 \mathrm{Nm}, 2960 \mathrm{rpm}$

$$
R_{s}=85.1 \mathrm{~m} \Omega, R_{r}=65.8 \mathrm{~m} \Omega
$$

$L_{s}=31.4 \mathrm{mH}, L_{r}=29.1 \mathrm{mH}, L_{m}=29.1 \mathrm{mH}$

$J=0.23 \mathrm{~kg} \cdot \mathrm{m}^{2}$

EV Mechanical AND AEROdynamic PaRAmeters

$m=1540 \mathrm{~kg}$ (two $70 \mathrm{~kg}$ passengers), $A=1.8 \mathrm{~m}^{2}, r=0.3 \mathrm{~m}$

$\mu_{r r 1}=0.0055, \mu_{r r 2}=0.056, C_{a d}=0.19, G=104, \eta_{g}=0.95$

$\mathrm{T}=57.2 \mathrm{Nm}$ (stall torque), $v_{0}=4.155 \mathrm{~m} / \mathrm{sec}$ $g=9.81 \mathrm{~m} / \mathrm{sec}^{2}, \rho=0.23 \mathrm{~kg} / \mathrm{m}^{3}$

\section{REFERENCES}

[1] S. Sakai et al., "Motion control in an electric vehicle with four independently driven in-wheel motors," IEEE/ASME Trans. Mechatronics, vol. 4, n¹, pp. 9-16, March 1996.
[2] G. Tao et al., "A novel driving and control system for direct-wheeldriven electric vehicle," IEEE Trans. Magnetics, vol. 41, n¹, pp. $497-$ 500, January 2005.

[3] L. Ju-Sang et al., "A neural network model of electric differential system for electric vehicle," in Proceedings of IEEE IECON'00, vol. 1, pp. 83-88, October 2000.

[4] T.J. Ren et al., "Robust speed-controlled induction motor drive based on recurrent neural network," Electric Power Systems Research, vol. 76 , pp. $1064-1074,2006$.

[5] R.S. Toqeer et al., "Speed estimation of an induction motor using Elman neural network," Electric Power Systems Research, vol. 55, pp. $727-730,2003$.

[6] X.Z. Gao et al., "A modified Elman neural network model with application to dynamical system identification," in Proceedings of IEEE ICSMC'96, vol. 2, pp. 1376-1381, Beijing (China), 1996.

[7] M.E.H. Benbouzid et al., "Electric motor drive selection issues for HEV propulsion systems: A comparative study," IEEE Trans. Vehicular Technology, vol. 55, n6, pp. 1756-1764, November 2006.

[8] A. Haddoun, M.E.H. Benbouzid and D. Diallo, "A loss-minimization DTC scheme for EV induction motors," IEEE Trans. Vehicular Technology, vol. 56, ${ }^{\circ} 1$, pp. 81-88, January 2007.

[9] A. Benchaïb et al., "Real-time sliding mode observer and control of induction motor," IEEE Trans. Industrial Electronics, vol. 46, n¹, pp. 128-138, February 1999.

[10] B. Asaii et al., "Neural network applications in control of electric vehicle induction machine drives," in Proceedings of IEE PEVSD'96, pp. 273-278, September 1996.

[11] B.K. Bose, Modern Power Electronics. Prentice Hall, New York 2002.

[12] S. Gair and al., "Electronic differential with sliding mode controller for a direct wheel drive electric vehicle," in Proceedings of IEEE ICM'04, pp. 98-103, June 2004.

[13] A. Haddoun, M.E.H. Benbouzid and D. Diallo, "Sliding mode control of EV electric differential system," in Proceedings of ICEM'06, Chania, Crete Island, Greece, September 2006.

[14] R.E. Colyer et al., "Comparison of steering geometries for multiwheeled vehicles by modelling and simulation," in Proceedings of IEEE CDC'98, vol. 3, pp. 3131-3133, December 1998.

[15] M. André et al., "Driving cycles for emissions measurements under European Conditions," SAE Paper, \# 950926, In Global Emission Experiences: Processes, Measurements, and Substrates (SP-1094), Warrendale (USA), pp. 193-205, 1995. 